\title{
Identification of a New Neuropeptide Precursor Reveals a Novel Source of Extrinsic Modulation in the Feeding System of Aplysia
}

\author{
Alex Proekt, ${ }^{1}$ Ferdinand S. Vilim, ${ }^{1}$ Vera Alexeeva, ${ }^{1}$ Vladimir Brezina, ${ }^{1}$ Allyson Friedman, ${ }^{1}$ Jian Jing, ${ }^{1}$ Lingjun Li, ${ }^{3}$ \\ Yuriy Zhurov, ${ }^{1}$ Jonathan V. Sweedler, ${ }^{2}$ and Klaudiusz R. Weiss ${ }^{1}$ \\ ${ }^{1}$ Department of Neuroscience, Mount Sinai School of Medicine, New York, New York 10029, ${ }^{2}$ Department of Chemistry and Beckman Institute, University \\ of Illinois, Urbana, Illinois 61801, and ${ }^{3}$ School of Pharmacy and Department of Chemistry, University of Wisconsin, Madison, Wisconsin 53705
}

The Aplysia feeding system is advantageous for investigating the role of neuropeptides in behavioral plasticity. One family of Aplysia neuropeptides is the myomodulins (MMs), originally purified from one of the feeding muscles, the accessory radula closer (ARC). However, two MMs, MMc and MMe, are not encoded on the only known MM gene. Here, we identify MM gene 2 (MMG2), which encodes MMc and MMe and four new neuropeptides. We use matrix-assisted laser desorption/ionization time-of-flight mass spectrometry to verify that these novel MMG2-derived peptides (MMG2-DPs), as well as MMc and MMe, are synthesized from the precursor. Using antibodies against the MMG2-DPs, we demonstrate that neuronal processes that stain for MMG2-DPs are found in the buccal ganglion, which contains the feeding network, and in the buccal musculature including the ARC muscle. Surprisingly, however, no immunostaining is observed in buccal neurons including the ARC motoneurons. In situ hybridization reveals only few MMG2-expressing neurons that are mostly located in the pedal ganglion. Using immunohistochemical and electrophysiological techniques, we demonstrate that some of these pedal neurons project to the buccal ganglion and are the likely source of the MMG2-DP innervation of the feeding network and musculature. We show that the MMG2-DPs are bioactive both centrally and peripherally: they bias egestive feeding programs toward ingestive ones, and they modulate ARC muscle contractions. The multiple actions of the MMG2-DPs suggest that these peptides play a broad role in behavioral plasticity and that the pedal-buccal projection neurons that express them are a novel source of extrinsic modulation of the feeding system of Aplysia.

Key words: MALDI mass spectrometry; cDNA cloning; neuropeptide processing; in situ hybridization; immunocytochemistry; feeding behavior

\section{Introduction}

In addition to classical neurotransmitters, many neurons also contain and release neuropeptides (Strand, 1999). These neuropeptides modulate a variety of processes in the nervous system and in the periphery. Furthermore, multiple neuropeptides often converge to modulate the very same processes. In this respect, one of the best-studied preparations is the Aplysia feeding system, in which a number of novel neuropeptides have been identified (Cropper et al., 1987a,b, 1988, 1994; Church and Lloyd, 1991; Church et al., 1993; Brezina et al., 1995, 1996; Vilim et al., 1996, 2000; Evans et al., 1999; Hurwitz et al., 2000; Morgan et al., 2000, 2002; Jing and Weiss, 2001; Sweedler et al., 2002; Koh et al., 2003).

Received July 15, 2005; revised Aug. 31, 2005; accepted Sept. 2, 2005.

This work was supported by National Institutes of Health (NIH) Grants DA13330, NS31609, MH35564, and P30DA18310. We gratefully acknowledge the generous gift of Aplysia CDNA libraries from Drs. G. Nagle and W. Sossin. We also thank Dr. E. C. Cropper for critical reading of this manuscript. Some Aplysia californica were provided by the National Resource for Aplysia at the University of Miami under NIH National Center for Research Resources Grant RR10294.

Correspondence should be addressed to Dr. K. R. Weiss, Department of Neuroscience, Mount Sinai School of Medicine, Box 1218, 1 Gustave Levy Place, New York, NY 10029. E-mail: klaudiusz.weiss@mssm.edu. DOI:10.1523/JNEUROSCI.2932-05.2005

Copyright $\odot 2005$ Society for Neuroscience $\quad$ 0270-6474/05/259637-12\$15.00/0
The experimental tractability of the Aplysia system has then made it possible to investigate how the convergence and interaction of these multiple modulators contribute to behavioral plasticity.

The myomodulins (MMs) have been particularly well studied. The MMs were originally purified from one of the feeding muscles, the accessory radula closer (ARC) muscle (Cropper et al., 1987b, 1991; Brezina et al., 1995). A gene that codes for MM peptides has been cloned (Miller et al., 1993). An antibody against the MMs stains one of the ARC motor neurons, neuron B16 (Miller et al., 1991). Immuno-electron microscopy has localized the MMs to dense-core vesicles at the B16-ARC neuromuscular junction (Vilim et al., 2000). Stimulation of B16 at physiological frequencies results in MM release (Vilim et al., 2000). Once released, the MMs modulate several ionic currents in the ARC muscle fibers (Brezina et al., 1994a,b) and alter a number of parameters of the ARC muscle contraction (Cropper et al., 1987b, 1991; Brezina et al., 1995; Orekhova et al., 2003). Computer modeling has shown how convergent actions of the MMs and other peptides that also modulate the ARC muscle contribute to behavioral plasticity (Brezina et al., 2003a,b, 2005).

However, our understanding of MM action has been incomplete. The origin of two of the MMs, MMc and MMe, has been 
elusive. Although purified from the ARC muscle (Brezina et al., 1995), they are not encoded on the known MM gene (Miller et al., 1993). [In previously published abstracts of this work, these two MMs were therefore referred to as "orphan myomodulins" (Friedman et al., 2003).]

In this study, we identify a gene that encodes these two missing members of the MM family. We refer to this gene as MM gene 2 (MMG2). In addition to MMc and MMe, the gene encodes four other neuropeptides, structurally unrelated to the MMs. Using matrix-assisted laser desorption/ionization time-of-flight mass spectrometry (MALDI), we demonstrate that these novel MMG2-derived peptides (MMG2-DPs), as well as MMc and $\mathrm{MMe}$, are actually synthesized and cleaved from the MMG2 precursor. We then demonstrate that some of the MMG2-DPs are bioactive in the feeding central pattern generator (CPG) and on the ARC muscle. Their actions are qualitatively distinct from those of MMc and MMe, and of the other MMs.

Surprisingly, however, MMG2 is not expressed in motor neuron $\mathrm{B} 16$ or $\mathrm{B} 15$, the other motor neuron of the ARC muscle. Instead, MMG2 is expressed in a population of neurons in the pedal ganglion. Through a combination of electrophysiological and immunohistochemical techniques, we demonstrate that these neurons project to the buccal ganglion and very likely to the $\mathrm{ARC}$ and other feeding muscles. In answering the question of the origin of $\mathrm{MMc}$ and $\mathrm{MMe}$, this study therefore reveals an unexpected new source of modulation that converges onto the ARC muscle and the Aplysia feeding system generally.

\section{Materials and Methods}

Animals. Aplysia californica weighing 100-350 g were obtained from the University of Miami Aplysia Research Facility (Miami, FL), Pacific Biomarine (Venice, CA), and Marinus (Long Beach, CA) and maintained at $14^{\circ} \mathrm{C}$.

Cloning. Standard molecular techniques (Sambrook et al., 1989) were used, except where noted. Seminested rapid amplification of cDNA ends (RACE) was performed on a Robocycler Gradient 40 (Stratagene, La Jolla, CA) with multiple annealing temperatures, as described previously (Furukawa et al., 2001; Sweedler et al., 2002). Degenerate antisense oligos designed to amino acid sequences of MMc and MMe were used in sequential PCR with two bluescript vector primers (BS1, ACCATGATTACGCCAAG; BS2, AATTAACCCTCACTAAAG). Either oligo-dTprimed Aplysia ganglionic cDNA Uni-Zap (Stratagene) lambda phage library or random-primed Aplysia ganglionic cDNA lambda phage library was used as the target for the PCR. Oligonucleotides were obtained from Operon (Alameda, CA) and used at a final concentration of 0.5-1 $\mu \mathrm{M}$. The PCR products were ligated into a T/A cloning vector (Invitrogen, Carlsbad, CA). Because some of the degenerate oligos were expected to amplify the known MM cDNA, we excluded the clones containing these inserts by hybridization with ${ }^{32} \mathrm{P}$-labeled random-primed cDNA of the known MM gene. Nonhybridizing clones were also screened by PCR to determine their size, and selected clones were then sequenced using dye termination. Using this approach, we identified a clone that contained the correct sequence of MMc and MMe flanked by dibasic cleavage sites as well as other likely peptide sequences. The insert from this clone was primed with random hexamers, labeled with ${ }^{32} \mathrm{P}$, and used to screen the Aplysia ganglionic cDNA libraries to identify clones encoding the full-length cDNA. At least three independent library clones were sequenced to obtain a full-length consensus sequence of the MMG2 precursor. The uni-Zap Aplysia ganglia cDNA libraries were a kind gift from Dr. G. Nagle (Marine Biomedical Institute, Galveston, TX), and the lamda Zap random-primed cDNA library was a kind gift from Dr. W. Sossin (McGill University, Montreal, Quebec, Canada).

Northern blot analyses. RNA was isolated using the acid-phenol method (Chomczynski and Sacchi, 1987). Northern blot analysis was performed on the RNA using formaldehyde/3-morpholinepropanesulfonic acid denaturing agarose gels (1.5\%) and downward trans- ferred with $20 \times$ saline-sodium phosphate-EDTA (SSPE) to positively charged nylon membranes (Biodyne B; Invitrogen, Rockville MD). The RNA was immobilized with UV (Stratalinker; Stratagene) and visualized by staining with $0.02 \%$ methylene blue in $0.3 \mathrm{M} \mathrm{Na}$-acetate, $\mathrm{pH} 5.5$. After destaining with $1 \%$ SDS, $1 \mathrm{~mm}$ EDTA, and $50 \mathrm{~mm} \mathrm{Na}_{3} \mathrm{PO}_{4}$, pH 7.2, the blot was prehybridized for $1 \mathrm{~h}$ at $50^{\circ} \mathrm{C}$ using $50 \%$ formamide, $10 \%$ dextran sulfate, $7 \%$ SDS, $10 \mathrm{~mm}$ EDTA, $50 \mu \mathrm{g} / \mathrm{ml}$ salmon sperm DNA, and $250 \mathrm{mM} \mathrm{Na}_{3} \mathrm{PO}_{4}, \mathrm{pH}$ 7.2. Heat-denatured, random-primed (New England Biolabs, Beverly, MA), ${ }^{32} \mathrm{P}$-dCTP-labeled cDNA probe (either $M M G 2$ or $M M$ ) was added, and hybridization was continued overnight at $50^{\circ} \mathrm{C}$. Blots were washed twice for $15 \mathrm{~min}$ at room temperature with $2 \times$ SSPE and $0.1 \%$ SDS, washed for $60 \mathrm{~min}$ at $50^{\circ} \mathrm{C}$ with $0.1 \times$ SSPE and $0.1 \%$ SDS, and exposed to film. Autoradiographs and methylene bluestained blots were scanned into Photoshop (Adobe Systems, San Jose, $\mathrm{CA})$ and compiled into the final figures.

In situ hybridization. In situ hybridization (ISH) was performed as described previously (Vilim et al., 2001). Aplysia ganglia were digested with $1 \%$ protease type IX (Sigma-Aldrich, St. Louis, MO) for $1 \mathrm{~h}$ at $30^{\circ} \mathrm{C}$ to loosen and facilitate the removal of connective tissue. After digestion, the ganglia were washed with artificial seawater (ASW; in mM: $460 \mathrm{NaCl}$, $10 \mathrm{KCl}, 55 \mathrm{MgCl}_{2}, 11 \mathrm{CaCl}_{2}$, and 10 HEPES, pH 7.6) and fixed overnight at $4^{\circ} \mathrm{C}$ with $4 \%$ paraformaldehyde (Electron Microscopy Sciences, Fort Washington, PA) in PBS. The ganglia were washed with several changes of PBS and $0.1 \%$ Tween 20 (PBT) and desheathed. The ganglia were dehydrated in an ascending methanol series and stored in 100\% methanol overnight at $-20^{\circ} \mathrm{C}$. After rehydration in a descending methanol series, the ganglia were washed with PBS and $0.3 \%$ Triton and refixed for 20 min with $4 \%$ paraformaldehyde and PBS. The ganglia were then washed with PBS, and the reactive groups were neutralized by washing first with $2 \mathrm{mg} / \mathrm{ml}$ glycine in PBS, then with $0.1 \mathrm{M}$ triethanolamine- $\mathrm{HCl}$ (TEA-HCl), $\mathrm{pH} 8.0$, and finally with $1 \mathrm{ml}$ of TEA-HCl containing $2.5 \mu \mathrm{l}$ of acetic anhydride. After several washes with PBT, the ganglia were prehybridized in Hyb-buffer ( $50 \%$ formamide, $5 \mathrm{~mm}$ EDTA, $5 \times$ SSC, $1 \times$ Dernhardt's solution, $0.1 \%$ Tween 20 , and $0.5 \mathrm{mg} / \mathrm{ml}$ yeast tRNA) overnight at room temperature and for $6-8 \mathrm{~h}$ at $50^{\circ} \mathrm{C}$ with fresh Hyb-buffer.

Digoxigenin-labeled cRNA was synthesized with T7 RNA polymerase using the MMG2 cDNA clone as a template and used as a probe at 2 $\mu \mathrm{g} / \mathrm{ml}$ in Hyb-buffer. The ganglia were hybridized overnight at $50^{\circ} \mathrm{C}$ and washed at $50^{\circ} \mathrm{C}(30$ min each in $50 \%$ formamide, $5 \times$ SSC, and $1 \%$ SDS; in $50 \%$ formamide, $2 \times$ SSC, and $1 \%$ SDS; in $50 \%$ formamide, $2 \times$ SSC, and $1 \%$ SDS; and in $0.2 \times$ SSC) to remove the unhybridized probe. The ganglia were washed three times for 10 min with PBT containing $0.2 \%$ BSA and blocked for $2 \mathrm{~h}$ with PBT containing $0.2 \%$ BSA and $10 \%$ normal goat serum (NGS). The ganglia were then incubated overnight at $4^{\circ} \mathrm{C}$ with a 1:200 dilution of alkaline phosphatase-conjugated antidigoxigenin antibody in PBT containing 0.2\% BSA and 1\% NGS. After washes with PBT to remove unbound antibody, the ganglia were washed with detection buffer $(100 \mathrm{~mm} \mathrm{NaCl}, 50 \mathrm{~mm} \mathrm{MgCl}, 0.1 \%$ Tween 20,1 mu levamisol, and $100 \mathrm{~mm}$ Tris $\mathrm{HCl}, \mathrm{pH}$ 9.5) and developed with $4.5 \mu \mathrm{l}$ of nitroblue tetrazolium and $3.5 \mu \mathrm{l}$ of 5-bromo-4-chloro-3-indolyl phosphate in $1 \mathrm{ml}$ of detection buffer (Roche Molecular Biochemicals, Indianapolis, IN). The staining reaction was monitored visually and stopped by washing with PBT when the level of staining was adequate. The stained ganglia were observed and photographed using a Nikon microscope (Morrell Instruments, Melville, NY) with epi-illumination against a white background. Photographs were taken with a Nikon CoolPix 990 digital camera, imported into Photoshop, and compiled into figures.

Antibodies. Antibodies to several of the peptides that were predicted from the MMG2 precursor were produced in rats as described previously (Fujisawa et al., 1999; Furukawa et al., 2001; Li et al., 2001; Sweedler et al., 2002). Briefly, the antigen was prepared by coupling synthetic peptide (SynPep, Dublin, CA) to BSA (catalog \#A0281; Sigma-Aldrich) using 1-ethyl-3-(dimethylaminopropyl)carbodiimide (EDC; catalog \#E7750; Sigma-Aldrich). The coupling was performed in $1 \mathrm{ml}$ of $50 \mathrm{~mm}$ $\mathrm{NaH}_{2} \mathrm{PO}_{4}, \mathrm{pH} 7.2$, containing $10 \mathrm{mg}$ of BSA, $1 \mathrm{mg}$ of peptide, and $25 \mathrm{mg}$ of EDC. The mixture was allowed to react overnight at $4^{\circ} \mathrm{C}$, and the coupled antigen was purified from the reaction using a Microcon-30 spinning at $13,800 \times g$ for $30 \mathrm{~min}$ at $4^{\circ} \mathrm{C}$. After washing the retentate four 
times with $0.4 \mathrm{ml}$ of $50 \mathrm{~mm} \mathrm{NaH}_{2} \mathrm{PO}_{4}, \mathrm{pH} 7.2$, it was resuspended in 0.5 $\mathrm{ml}$ of the same buffer and transferred to a new tube.

For each antigen, two male Sprague Dawley rats (250-300 g; Taconic, Germantown, NY) were immunized by intraperitoneal injection with either $12.5 \mu \mathrm{l}(\sim 250 \mu \mathrm{g}$; rat 1$)$ or $25 \mu \mathrm{l}(\sim 500 \mu \mathrm{g}$; rat 2$)$ of antigen in an emulsion of $0.3 \mathrm{ml}$ of PBS and $0.3 \mathrm{ml}$ of Freund's complete adjuvant. At days 21 and 42, the rats were boosted by intraperitoneal injection with either $6.25 \mu \mathrm{l}(\sim 125 \mu \mathrm{g}$; rat 1) or $12.5 \mu \mathrm{l}(\sim 250 \mu \mathrm{g}$; rat 2$)$ of antigen in an emulsion of $0.3 \mathrm{ml}$ of PBS and $0.3 \mathrm{ml}$ of Freund's incomplete adjuvant. The animals were killed by decapitation at $49 \mathrm{~d}$, and the blood was harvested and processed for serum. Sera were aliquoted, frozen and lyophilized, or stored at $4^{\circ} \mathrm{C}$ with EDTA ( $25 \mathrm{~mm}$ final concentration) and thimerosal ( $0.1 \%$ final concentration) added as stabilizers. Specificity of immunostaining was confirmed by preincubation of the primary antibody with $10^{-4} \mathrm{M}$ of the corresponding synthetic peptide, which abolished the staining.

Immunocytochemistry. Immunocytochemistry was performed as described previously (Vilim et al., 1996; Fujisawa et al., 1999; Furukawa et al., 2001). Tissues were fixed in freshly prepared fixative (4\% paraformaldehyde, $0.2 \%$ picric acid, $25 \%$ sucrose, and $0.1 \mathrm{M} \mathrm{NaH}_{2} \mathrm{PO}_{4}, \mathrm{pH} 7.6$ ) for either $3 \mathrm{~h}$ at room temperature or overnight at $4^{\circ} \mathrm{C}$. After washes with PBS to remove the fixative, ganglia from large animals were desheathed to expose the neurons. Ganglia from small animals (10-15 g) were processed without desheathing. All subsequent incubations were done at room temperature. Tissue was permeabilized and blocked by overnight incubation in blocking buffer (BB; 10\% normal donkey serum, 2\% Triton X-100, 1\% BSA, $154 \mathrm{~mm} \mathrm{NaCl}, 50 \mathrm{~mm}$ EDTA, 0.01\% thimerosal, and $10 \mathrm{mM} \mathrm{Na}_{2} \mathrm{HPO}_{4}, \mathrm{pH}$ 7.4). The primary antibody was diluted 1:250 in BB and incubated with the tissue for $4-7 \mathrm{~d}$. The tissue was then washed twice per day for 2-3 d with washing buffer (WB; $2 \%$ Triton X-100, 1\% BSA, $154 \mathrm{~mm} \mathrm{NaCl}, 50 \mathrm{~mm}$ EDTA, $0.01 \%$ thimerosal, and $10 \mathrm{~mm} \mathrm{Na}_{2} \mathrm{HPO}_{4}$, $\mathrm{pH}$ 7.4). After the washes, the tissue was incubated with a 1:500 dilution of secondary antibody (lissamine rhodamine donkey anti-rat; Jackson ImmunoResearch, West Grove, PA) for 2-3 d. The tissue was then washed twice with WB for $1 \mathrm{~d}$ and four times with storage buffer (1\% BSA, $154 \mathrm{~mm} \mathrm{NaCl}, 50 \mathrm{~mm}$ EDTA, $0.01 \%$ thimerosal, and $10 \mathrm{~mm}$ $\mathrm{Na}_{2} \mathrm{HPO}_{4}, \mathrm{pH}$ 7.4) for $1 \mathrm{~d}$.

Double-labeling experiments were performed as described previously (Vilim et al., 1996, 2000). In these experiments, in addition to the antiMMG2 antibodies, we have used either anti-MMa antibodies (Miller et al., 1991; Vilim et al., 2000) or anti-buccalin antibodies (Miller et al., 1992). Both the anti-MMa and anti-buccalin antibodies were prepared in rabbits. Thus, in addition to the rhodamine donkey anti-rat antibody, we stained the tissues with fluoroscein donkey anti-rabbit secondary antibody (Jackson ImmunoResearch).

The tissues were then stored at $4^{\circ} \mathrm{C}$ and viewed and photographed on a Nikon microscope equipped with epifluorescence. The black and white images were collected using filters with characteristics appropriate for distinguishing between the fluorophors. The negatives of the images collected with the rhodamine and fluoroscein filters are shown in the figures to enhance the visibility of the stained neuronal processes. The same field of view is shown for the images collected with the rhodamine and fluoroscein filters.

Backfills. Backfills, as described previously (Furukawa et al., 2001; Sweedler et al., 2002), did not produce sufficient intensity of staining and had to be modified to an older version of the method. Cerebral ganglia with attached pleural and pedal ganglia from $10 \mathrm{~g}$ animals were pinned in Sylgard-lined dishes. The cerebro-buccal connective (CBC) was isolated from the ganglia in a silicone grease well and a subchamber constructed from a $1 \mathrm{~cm}$ cylinder cut from a $5 \mathrm{cc}$ syringe. The subchamber was then washed with $0.5 \mathrm{ml}$ of distilled water to remove salt, the backfill solution ( $20 \mu \mathrm{l}$ of saturated solution of biocytin in water) was applied to the CBC, and the preparation was incubated for $24 \mathrm{~h}$ at $15^{\circ} \mathrm{C}$. The incubation medium for the ganglion was ASW containing 1\% BSA (catalog \#A9647; Sigma-Aldrich), $0.1 \%$ amicase (catalog \#A2427; Sigma-Aldrich), and $0.03 \%$ dextrose. The incubation medium also contained $0.1 \%$ collagenase, which loosened the sheath during the incubation. The ganglia were washed several times with ASW before fixation and processed for immu- nostaining, as above except that streptavidin-fluorescein was also included with the secondary antibody to detect the backfilled biocytin.

Mass spectrometry. Based on the mRNA expression results, individual neurons from pedal ganglia were isolated and prepared as described previously (Li et al., 2000). Briefly, the pedal ganglion was immersed in regular 2,S-dihydroxybenzoic acid (DHB) matrix solution $(10 \mathrm{mg} / \mathrm{ml}$ deionized water). Isolated neurons were transferred onto a MALDI sample plate containing $0.5 \mu \mathrm{l}$ of either regular DHB matrix solution or concentrated DHB $(50 \mathrm{mg} / \mathrm{ml})$ in acetone:water (4:1). The neurons on the plate were smashed before drying at ambient temperature. Samples were either frozen or analyzed immediately. MALDI mass spectra were obtained using a Voyager DE STR mass spectrometer (PE Biosystems, Framingham, MA). A pulsed nitrogen laser $(337 \mathrm{~nm})$ was used as the desorption/ionization source. A custom-designed pinhole was used to reduce the laser spot size to $\sim 25 \mu \mathrm{m}$ diameter on the sample plate, and positive-ion mass spectra were acquired using reflectron mode. A $20 \mathrm{kV}$ accelerating voltage, $71.8 \%$ grid voltage, $0.03 \%$ guide wire voltage, and a delay time of $200 \mathrm{~ns}$ were used. The spectra were smoothed by averaging 100-256 scans. For MALDI post-source decay (PSD) analysis, $20 \mathrm{kV}$ total acceleration voltage, $75 \%$ grid voltage, $0.03 \%$ guide wire voltage, and 75 ns delay time was used. Using a timed ion selector, different precursor ions can be selected and subjected to fragmentation. Under these experimental conditions, the mass accuracy of the precursor ion was within $30 \mathrm{ppm}$, and the average error on the mass assignment of the PSD ions was better than $0.3 \mathrm{U}$. Spectra were obtained by accumulating data from 100-256 laser shots. To obtain complete PSD spectra, a series of reflectron spectral segments were acquired, each optimized to focus fragment ions within different $\mathrm{m} / \mathrm{z}$ ranges (Spengler, 1997). Each segment was stitched together using the Biospectrometry Workstation software to generate a composite PSD spectrum. For MALDI in-source decay (ISD) analysis (Brown and Lennon, 1995) of liquid chromatography (LC) fractions, 110 Aplysia buccal ganglia were homogenized, extracted for peptides, and separated using microbore HPLC. Individual LC fractions were screened by MALDI; $0.5 \mu \mathrm{l}$ of each LC fraction was deposited onto a MALDI sample plate, followed by the same volume of 2,5dihydroxybenzoic acid matrix solution. Thus, $>95 \%$ of each fraction was available for additional assays. ISD mass spectra were acquired in the linear mode, the acceleration voltage was $20 \mathrm{kV}$, and laser power was applied well above the threshold value to facilitate fragmentation. The delay time used was 300-400 ns. Mass spectra were averaged over 100 laser shots and smoothed (19 points, Savitsky-Golay).

Electrophysiology. Animals weighing 150-250 g were anesthetized by injection of isotonic $\mathrm{MgCl}_{2}$ (337 mM). Cerebral and buccal ganglia were desheathed to expose the cells of interest. The ganglia were then pinned out in a Sylgard-lined recording dish that contained $\sim 1.5 \mathrm{ml}$ of ASW (in mм: $460 \mathrm{NaCl}, 10 \mathrm{KCl}, 55 \mathrm{MgCl}_{2}, 11 \mathrm{CaCl}_{2}$, and 10 HEPES, pH 7.6). The preparation was perfused continuously with ASW at $0.3 \mathrm{ml} / \mathrm{min}$ and cooled to $14-17^{\circ} \mathrm{C}$.

Intracellular recordings were made with glass microelectrodes filled with recording solution $(2 \mathrm{M} \mathrm{K}$-acetate and $200 \mathrm{mM} \mathrm{KCl})$ and beveled to $8-15 \mathrm{M} \Omega$. In some cases, the tip of the microelectrode was filled with $3 \%$ carboxyfluoroscein. The dye was injected into the neurons by passing negative current for $15 \mathrm{~min}$. These dye-injected preparations were then stained with the anti-MMG2-DP antibodies.

To monitor feeding motor programs, we used a combination of intracellular and extracellular recording. Intracellular voltage recordings were amplified with either an Axoclamp 2B amplifier (Molecular Devices, Union City, CA) or Getting 5A amplifiers. Extracellular recordings and stimulation were performed using suction electrodes manufactured from polyethylene tubing connected to a differential AC amplifier (model 1700; A-M Systems, Carlsborg, WA). All signals were acquired simultaneously at $5 \mathrm{kHz}$ with a Digidata 1322A data-acquisition system (Molecular Devices). Signals were then analyzed using Clampfit 9 (Molecular Devices). Axum 5 (Mathsoft, Cambridge, MA) and SigmaPlot 8 (Systat Software, Point Richmond, CA) were used to generate figures.

Identification and characterization of feeding motor programs. In Aplysia, each cycle of the feeding motor program begins with the radula protraction phase, followed by the radula retraction phase (Hurwitz and Susswein, 1996; Hurwitz et al., 1996, 1997; Jing and Weiss, 2001, 2002; 
Morgan et al., 2002; Koh et al., 2003; Proekt and Weiss, 2003; Proekt et al., 2004). The radula protraction phase was defined to be coincident with the burst of electrical activity in the I2 nerve (Hurwitz and Susswein, 1996; Hurwitz et al., $1996,1997)$. The radula retraction phase was defined as lasting from the end of the I 2 nerve burst to the end of the buccal nerve 2 (Bn2) burst (Morton and Chiel, 1993a,b). Ingestive and egestive motor programs are distinguished by the way in which radula closure activity is coupled to the protraction-retraction sequence. In ingestive programs, radula closure occurs predominantly in the retraction phase, whereas in egestive programs, it occurs predominantly during the protraction phase (Morton and Chiel, 1993a,b; Jing and Weiss, 2001, 2002; Morgan et al., 2002; Proekt et al., 2004). We monitored radula closure by recording firing of the radula closer motor neuron B8 (Morton and Chiel, 1993a,b). We also recorded firing of neurons B4/B5.

We used two previously characterized input stimuli to elicit the motor programs: the command-like cerebro-buccal interneuron 2 (CBI-2) (Rosen et al., 1991; Morgan et al., 2000, 2002; Jing and Weiss, 2001) and the esophageal nerve (Chiel et al., 1988; Horn et al., 2004; Proekt et al., 2004). CBI-2 was stimulated to fire action potentials at $8-12 \mathrm{~Hz}$ for the duration of the protraction phase so as to elicit a single motor program every $90 \mathrm{~s}$. The esophageal nerve was stimulated with $3 \mathrm{~ms}$ current pulses delivered at $6-7 \mathrm{~Hz}$. A $5 \mathrm{~s}$ burst of these pulses was delivered every minute. The amplitude of the pulses was adjusted such that each burst elicited exactly one motor program.

ARC neuromuscular preparation. We used the standard preparation for recording motor neuron-elicited contractions of the ARC muscle (Weiss et al., 1979; Orekhova et al., 2003). Briefly, the preparation consisted of the buccal ganglia, the ARC muscles, and the connecting buccal nerve 3, through which the ARC is innervated by the motor neurons B15 and B16. One of the ARC muscles was pinned out in a separate chamber and connected to an isotonic transducer (model 60-3000; Harvard Apparatus, Holliston MA) to measure the length of the muscle contracting against a light counterbalancing load. Motor neuron B15 was stimulated to fire 1.5 or $2 \mathrm{~s}$ bursts of spikes at a frequency necessary to produce contractions of moderate amplitude every $20 \mathrm{~s}$. Peptides were added to the muscle chamber only.

\section{Results \\ Cloning of MMG2}

Several attempts were made to identify the mRNA encoding MMc and MMe by using semi-nested RACE (see Materials and Methods) with degenerate oligos targeting the amino acid sequences of these peptides. Initially, we designed the degenerate oligos in the antisense direction to the MMc amino acid sequence and used PCR to amplify oligo-dT-primed Aplysia CNS cDNA. Because these attempts were unsuccessful, we switched to using a sense-oriented degenerate oligo to the MMe amino acid sequence RGLQMLRLG (oligo sequence MGIGGIYTICARATGYTIMGIYTIGG) and used a random-primed Aplysia CNS cDNA library as a target for the PCR.

Because this PCR was expected to amplify not only new sequences but also the known MM cDNA, we used a Southern blot-based screen to exclude the known MM sequences. We first subcloned all PCR products of the semi-nested RACE and subjected them to Southern blot analysis using radioactively labeled random-primed MM cDNA as a probe. We excluded all clones that hybridized and sequenced all other clones. Some of these clones contained the sequence of MMe flanked by the expected downstream dibasic cleavage site. One of these inserts was used to generate random-primed probes that were then used to screen

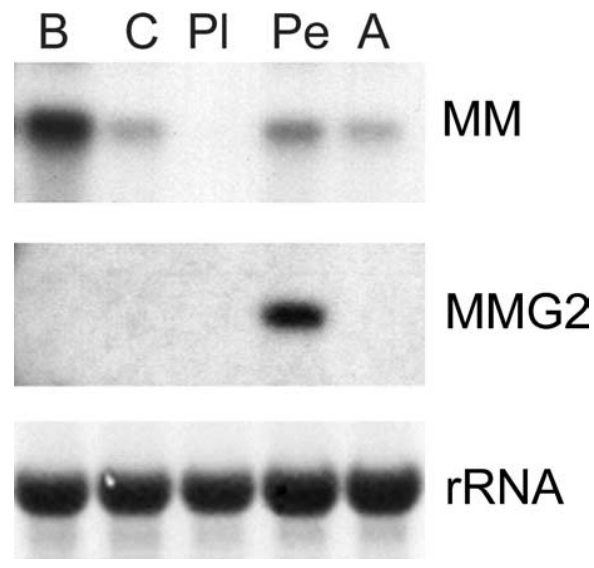

Figure 2. Comparison of expression of $M M$ and $M M G 2$ mRNAs. Northern blots with either MM or MMG2 probes using RNA extracted from buccal (B), cerebral (C), pleural (PI), pedal (Pe), and abdominal (A) ganglia are shown. Ribosomal RNA (rRNA) bands are shown to demonstrate that the same amount of RNA was loaded into each lane.

lambda oligo-dT-primed Aplysia CAN libraries to identify fulllength clones. After sequencing several of these clones, we arrived at a consensus sequence 2072 nucleotides long containing a 720 bp open reading frame (GenBank accession number DQ186993), which we named MMG2.

The open reading frame predicted the 240 aa precursor protein shown in Figure 1. The predicted protein contained a signal peptide (white rectangle) with a predicted cleavage between $\mathrm{Ala}^{23}$ and $\operatorname{Gln}^{24}$ (Nielsen et al., 1997). It also contained single copies of MMc and MMe. Four other fragments of the precursor protein were detected in the amidated form (see below, Processing of the MMG2 precursor protein). We refer to these fragments as MMG2-DPs, shown by the gray rectangles in Figure 1. The molecular weights of some of the non-amidated connecting peptides (underlined in black) also matched peaks detected by MALDI (see Fig. 4) (Li et al., 1998; Sweedler et al., 2002). Although these connecting peptides could potentially be bioactive as in the study by Brezden et al. (1999), here we have focused on the amidated peptides derived from the MMG2 precursor protein.

\section{Expression of MMG2 mRNA in the nervous system}

We used Northern blot analysis to compare the overall distribution of the known MM and the new MMG2 mRNAs in the central 


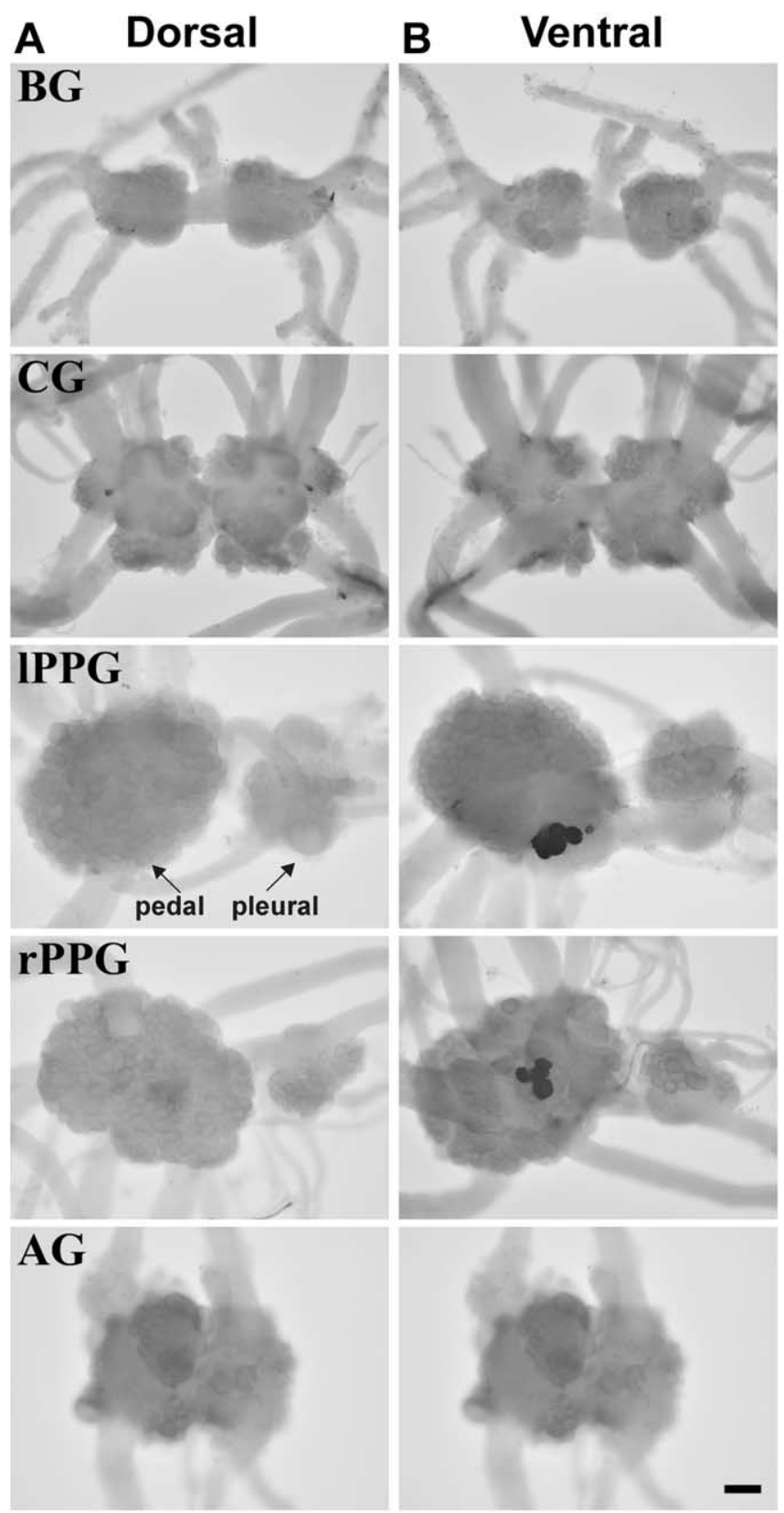

Figure 3. ISH analysis of the expression of MMG 2 in the CNS. Dorsal $(\boldsymbol{A})$ and ventral $(\boldsymbol{B})$ views of the central ganglia are shown. Scale bar, $100 \mu \mathrm{m} . \mathrm{BG}$, Buccal ganglion; $\mathrm{CG}$, cerebral ganglion; IPPG, left pleural and pedal ganglia; rPPG, right pleural and pedal ganglia; AG, abdominal ganglion.

ganglia (Fig. 2$)$. The $M M$ mRNA $(\sim 1.5 \mathrm{~kb})$ was more widely distributed in the central ganglia than the MMG2 mRNA $(\sim 2$ $\mathrm{kb}$ ). The $M M \mathrm{mRNA}$ was expressed mostly in the buccal ganglion but was also expressed in the cerebral, pedal, and abdominal ganglia. In contrast, the MMG2 mRNA was detected only in the pedal ganglion.

We then used ISH to further define the expression of the MMG2 mRNA (Fig. 3). Consistent with the findings of the Northern blot analysis, the pedal ganglion contained the most MMG2-expressing neurons. Specifically, a cluster of MMG2expressing neurons was observed on the ventral surface of the ganglion. In the cerebral ganglion, a few small $M M G 2$-expressing neurons were observed, including an asymmetrical neuron on the dorsal surface. Given the relatively small size and number of these neurons, it is not surprising that the MMG2 mRNA in the cerebral ganglion was below the level of detection in the Northern blot analysis. No MMG2-expressing neurons were observed in the buccal, pleural, or abdominal ganglia.

\section{Processing of the MMG2 precursor protein}

To identify the peptides cleaved from the MMG2 precursor, we used the cluster of MMG2-expressing pedal neurons as a target for MALDI analysis. Figure $4 A-C$ shows a representative MALDI mass spectrum from a single pedal neuron. With the available precursor sequence, many of the peaks in the spectrum could be correlated with peptides predicted by the sequence. We were able to identify peaks corresponding to the amidated forms of MMc and MMe as well as amidated forms of the new peptides MMG2DPa, MMG2-DPb, MMG2-DPd, and MMG2-DPf. MMG2-DPb found in both the pyro-Glu (pQPPLPRYamide) and non-pyroGlu (QPPLPRYamide) forms (Fig. 4A). Both amidation and pyro-glutamination are known post-translational modifications of many neuropeptides that are thought to protect them from proteolysis (Strand, 1999). All peptides were identified with an average mass accuracy better than $50 \mathrm{ppm}$, suggesting that the assignments were made correctly. To further verify the assignments, we performed PSD experiments that confirmed some of the peptide sequences (data not shown).

In addition to the peaks corresponding to the posttranslationally modified neuropeptides, peaks corresponding to the various connecting peptides were also observed in the mass spectrum. Among these peptides, a partial sequence of 24 aa residues was confirmed for the 29-mer connecting peptide $\mathrm{Gly}_{84^{-}}$ Ser $_{112}$ by MALDI-ISD analysis (data not shown). Interestingly, this peptide is one of the most easily MALDI-detectable masses in several major nerves including the cerebro-buccal and pleuroabdominal connectives (Li et al., 1998).

Altogether, these results strongly suggest the processing scheme for the MMG2 precursor that is shown in Figure $4 D$. Some of the processing sites correspond to known consensus sites of the furin/prohormone convertase family of peptideprocessing enzymes. In addition, some processing sites correspond to Leu-Leu prohormone cleavage, possibly by enzymes of the endothelin converting enyme family, which was demonstrated previously to occur in the Aplysia CNS (Hummon et al., 2002). Figure $4 D$ also shows trimming of amino acids from the $C$ terminus of some of the peptides, possibly by a carboxypeptidaselike enzyme, and may reflect peptides that are in various stages of degradation.

\section{Distribution of MMG2-DPs in the CNS}

We raised antibodies against MMG2-DPa (GGSLDALRSGHQVPMLRAamide) because it was very different from the known MMs. We also raised antibodies to both the pyro-Glu and the non-pyro-Glu forms of MMG2-DPb, using paraformaldehyde/glutaraldehyde for conjugation to BSA. The neuronal somata stained with the MMG2-DPa antibody (Fig. 5) were essentially identical to those observed with ISH (Fig. 3). A single cluster of neurons in the pedal ganglion and three distinct neurons in the cerebral ganglion were stained with the antibody. We also observed a density of immunostaining deep in the cerebral ganglion in the region of the F- and C-clusters. The MMG2-DPb antibodies gave very similar results (data not shown).

The concordance between the ISH and immunohistochemistry results suggests that the antibodies raised against the MMG2DPs were specific. Unlike ISH, the immunohistochemistry allowed us to visualize not only the MMG2-DP-expressing somata 

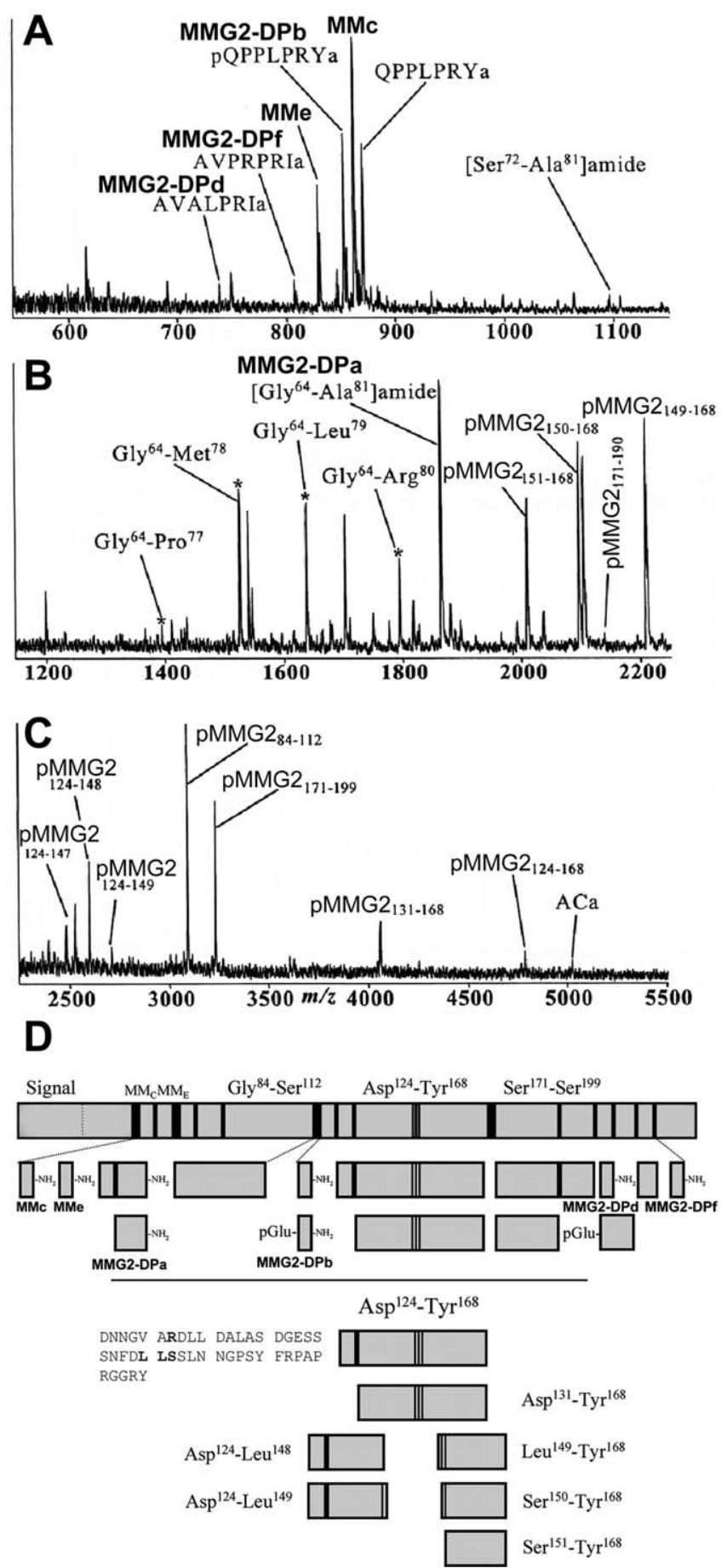

Figure 4. MALDI analysis of individual pedal neurons reveals MMG2 precursor processing. A representative mass spectrum of a single Aplysia pedal neuron is shown. The mass scale is divided into low (m/z 550-1150) (A), middle ( $\mathrm{m} / \mathrm{z} 1200-2250)(\boldsymbol{B})$, and high $(\mathrm{m} / \mathrm{z} 2450$ 5500) (C) mass ranges. Mass spectral peaks were assigned based on the observed mass and the sequence of MMG2. D, Summary of the MMG2 precursor processing. Solid vertical lines represent cleavage sites, with black bars indicating dibasic sites that are entirely cleaved. Lightly shaded blocks represent peptides detected by MALDI. The processing of connecting peptide Asp ${ }^{124}$-Tyr ${ }^{168}$, highlighted below, shows numerous novel processing sites involving Leu-Leu and Leu-Ser cleavages.

but also the distribution of MMG2-DP-containing neuronal processes. In contrast to the very sparse distribution of the MMG2expressing somata, the MMG2-DP-containing processes were observed in the neuropil of all of the central ganglia, including the

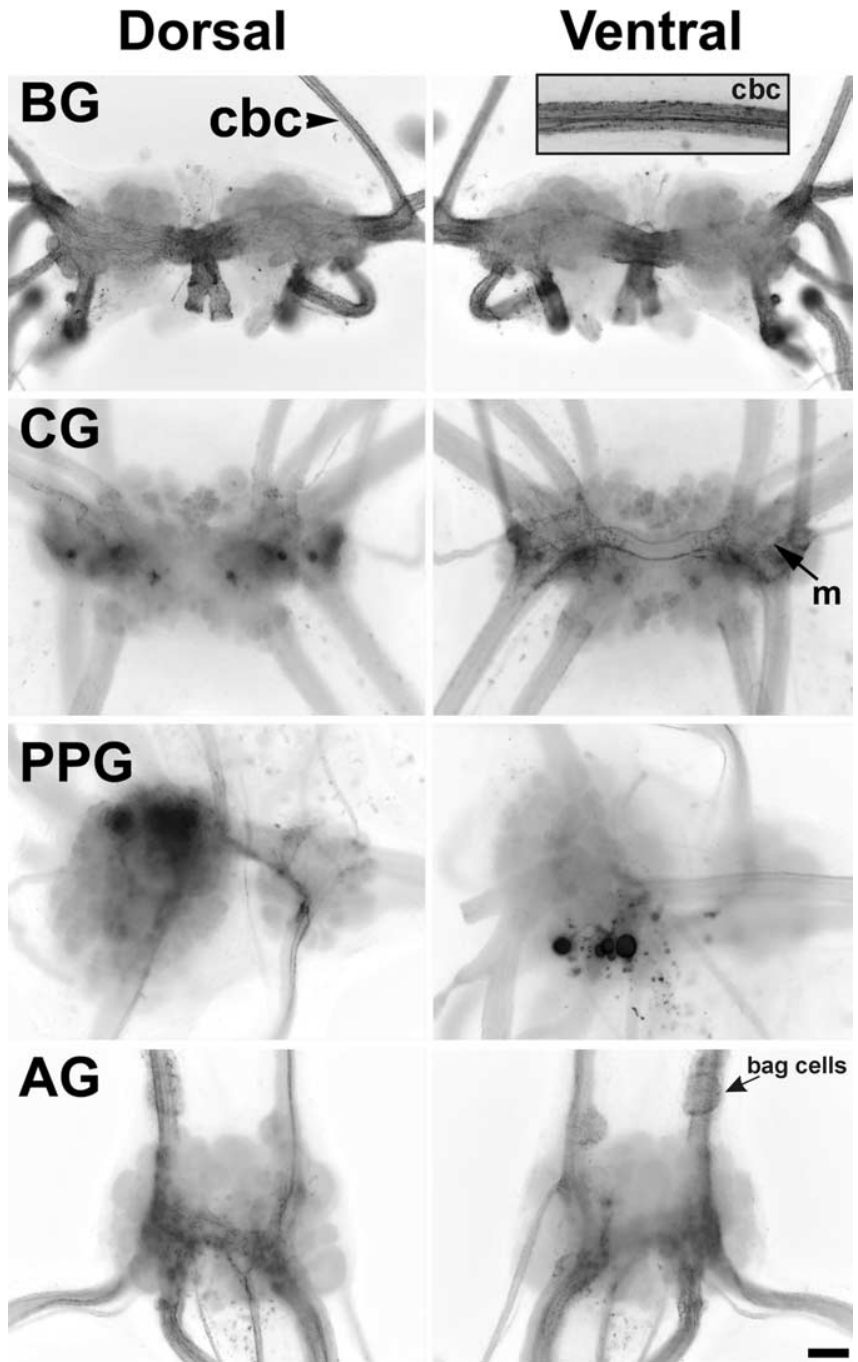

Figure 5. MMG2-DP immunostaining in the CNS. All panels are negatives of the black and white images collected at the appropriate filter settings. The inset above the ventral view of the buccal ganglion shows an enlarged view of the CBC illustrating an MMG2-DP-containing process. Scale bar, $100 \mu \mathrm{m}$. BG, Buccal ganglion; (G, cerebral ganglion; PPG, pleural and pedal ganglia; AG, abdominal ganglion; $m, M$-cluster; cbc, cerebro-buccal connective.

buccal ganglion (Fig. 5). Staining was observed in all of the buccal nerves and in the CBC. Stained processes were also observed in the $\mathrm{M}$ - and E-clusters of the cerebral ganglion, a region containing CBIs that project to the buccal ganglion (Rosen et al., 1991). Neither the immunocytochemistry nor ISH, however, stained somata in the M-cluster, suggesting that the CBIs are not the source of the MMG2-DPs in the feeding system.

Immunostained processes were also observed in the pleuroabdominal connective. These findings were consistent with MALDI analysis that detected MMc and MMe in the connectives and nerves of the abdominal ganglion ( $\mathrm{Li}$ et al., 1998). In the abdominal ganglion, immunostained processes appeared to envelop the region containing the bag cells.

\section{Distribution of MMG2-DPs in the periphery}

Next, we used the MMG2-DPa antibody to stain the ARC muscle (Fig. 6A). We also stained the same muscle with an antibody to buccalin (Miller et al., 1992), a neuropeptide that is present in both of the ARC motor neurons, B15 and B16 (Cropper et al., 1988, 1990) (Fig. 6B). These double-labeling experiments were 


\section{A. ARC (MMG2-DPa)}

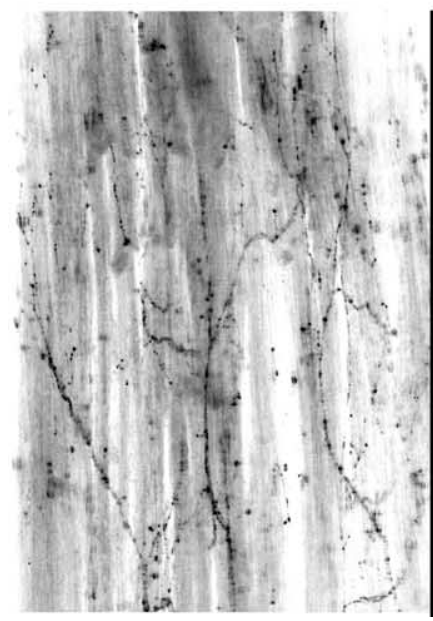

B. ARC (Buc)

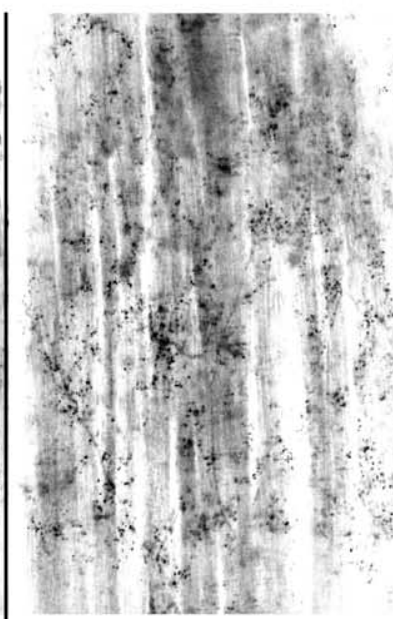

C. 12 (MMG2-DPa)

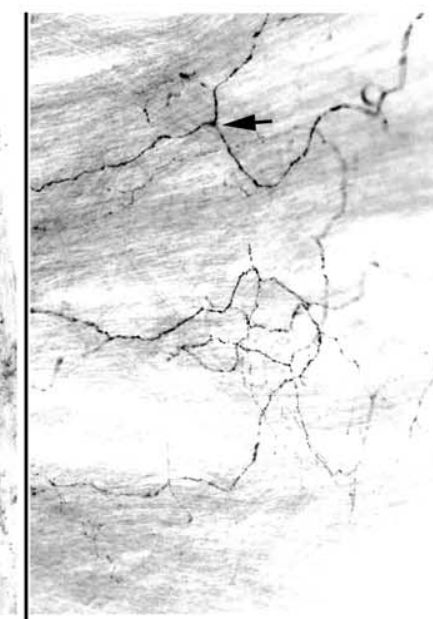

D. 12 (MM)

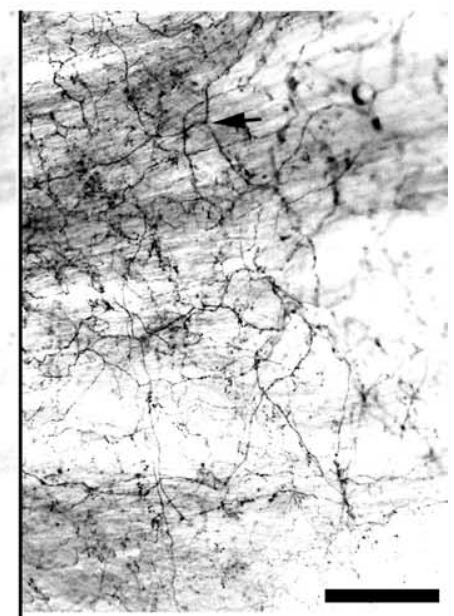

Figure 6. MMG2-DP immunostaining in the ARC and 12 muscles. All panels are negatives of the black and white images collected at the appropriate filter settings. $\boldsymbol{A}$, Staining of the ARC muscle with the MMG2-DPa antibody. B, Same field of view as in $\boldsymbol{A}$ stained with the buccalin antibody (Buc). C, Staining of the I2 muscle with the MMG2-DPa antibody. D, Same field of view as in $\boldsymbol{C}$ stained with the MMa antibody. The arrows in $\mathbf{C}$ and $\boldsymbol{D}$ point to a process stained with both the MMG2-DPa and MMa antibodies. Scale bar, $100 \mu \mathrm{m}$.

performed as described in Materials and Methods. The negatives of the black and white images collected with the appropriate filters to distinguish between the two fluorophors are shown to enhance the visualization of the stained neuronal processes. The two antibodies stained different, nonoverlapping sets of processes in the muscle. Thus, the MMG2-DP-containing processes were distinct from those of B15 and B16. This agreed with the lack of staining of the B15 and B16 somata in the buccal ganglion found with both ISH and immunocytochemistry. The antibody raised against pyro-MMG2-DPb also recognized processes in the ARC muscle that did not costain with the antibody against buccalin (data not shown).

In addition to being innervated by $\mathrm{B} 15$ and $\mathrm{B} 16$, the $\mathrm{ARC}$ muscle is also innervated by the serotonergic metacerebral cells (MCCs) (Weiss et al., 1975, 1978). However, the MCCs are not known to contain any neuropeptides and did not stain for MMG2-DPs (Figs. 4, 5).

Because MMG2-DP-containing processes were observed in all of the buccal nerves that course out to the feeding musculature, we wanted to see whether the MMG2-DPs were more widely distributed in the musculature. Of particular interest was the I2 radula protractor muscle. Like the ARC, the I2 muscle is subject to modulation, indeed by some of the same modulators including the MMs and serotonin (Hurwitz et al., 2000). The I2 muscle also contained processes staining for MMG2-DPa (Fig. 6C). These processes also stained with an antibody raised against MMa (Fig. $6 D$; the arrows in Fig. 6, $C$ and $D$, indicate one double-labeled process). This costaining presumably occurred because the MMa antibody recognizes all MMs, including MMc and MMe derived from MMG2. However, the MMa antibody also stained processes in the I2 muscle that did not stain with the MMG2-DPa antibody. These were likely processes of the I2 motor neurons B31/32 and B61/62, which contain the MMs (Hurwitz et al., 2000).

Identification of pedal-buccal projection neurons as the likely source of MMG2-DPs in the feeding system

Thus, the MMG2-DP-containing processes in both the ARC and I2 muscles could not be attributed to any of the known sources of innervation of the muscles. Our ISH and immunostaining results suggested two possibilities for the source of this innervation: the
MMG2-DP-containing neurons in the cerebral and pedal ganglia. Based on previous findings (Rosen et al., 1991), however, we knew that the MMG2-DP-containing neurons in the cerebral ganglion are located in areas that do not contain neurons that directly project to the buccal ganglion via the CBC. Indeed, backfills of the CBCs into the cerebral ganglion, followed by immunohistochemistry, confirmed that none of the backfilled cerebral neurons stained for MMG2-DPs (data not shown).

However, backfills of the $\mathrm{CBC}$ that extended to the pedal ganglion (Fig. 7A) labeled several of the pedal neurons that stained for MMG2-DPs (Fig. 7B). To confirm that the pedal MMG2-DPcontaining neurons projected to the buccal ganglion, we stimulated these neurons to fire action potentials while recording activity in the CBC. We then filled several neurons, the spikes of which we recorded in the $\mathrm{CBC}$, with carboxyfluoroscein (Fig. 7C1). A representative recording of one such neuron is shown in Figure 7C2. Every intracellularly triggered action potential in the pedal neuron corresponded in a one-to-one manner to a unit recorded extracellularly in the $\mathrm{CBC}$. We then stained the pedal ganglion with the MMG2-DPa antibody (Fig. 7C3). The staining for MMG-DPs was found in several of the carboxyfluorosceinfilled neurons. Thus, several of the pedal MMG2-DP-containing neurons projected to the buccal ganglion via the $\mathrm{CBC}$. In location and morphology, these neurons resembled a group of neurons described previously as pedal-buccal projecting neurons ( $\mathrm{P}$ BPNs) by Robie et al. (2003). Importantly, Robie et al. (2003) showed that the P-BPNs project beyond the buccal ganglion, out through most of the buccal nerves to the buccal musculature.

However, one neuron that consistently stained for MMG2DPs (Fig. 7C3, asterisk) did not project to the CBC. Instead, we recorded its spikes in the pedal-abdominal connective (data not shown). This neuron could therefore be the source of the MMG2DPs that we found around the bag cells in the abdominal ganglion.

\section{Physiological action of MMG2-DPs in the periphery}

The wide distribution of MMG2-DP-containing neuronal processes in the nervous system suggested that these peptides may play both central and peripheral modulatory roles in the feeding system. To characterize the peripheral actions of the MMG2- 
DPs, we studied motor neuron-elicited contractions of the ARC muscle. Because the effects of MMc and MMe have been investigated previously (Brezina et al., 1995), we focused on the effects of the novel MMG2DPs. First, we characterized the effect of the equimolar mixture of MMG2-DPa, MMG2-DPb, MMG2-DPd, and MMG2DPf. This effect was completely reproduced by MMG2-DPb alone, and no other MMG2-DP had any effect. Therefore, we used MMG2-DPb alone in all subsequent experiments on the ARC muscle.

In these experiments, we repeatedly stimulated motor neuron B15 or B16 to fire a burst of action potentials at a fixed frequency such that each burst elicited a muscle contraction. A representative recording is shown in Figure $8 \mathrm{~A}$. (The first and last bursts of action potentials and the corresponding contractions are shown on an expanded time scale.) Application of MMG2$\mathrm{DPb}$ resulted in a tonic contracture, an elevation of the baseline of muscle contraction. Unlike the MMs, including MMc and MMe (Cropper et al., 1987b, 1991; Brezina et al., 1995), MMG2-DPb had no consistent effect on the amplitude or relaxation rate of the phasic contraction. MMG2-DPa, MMG2-DPd, and MMG2-DPf tested separately had no effects on the contraction amplitude, relaxation rate, or tonic contracture of the muscle.

Figure $8 B$ shows the dose-response curve for the contracture induced by MMG2-DPb. The half-maximally effective concentration was $<10^{-7} \mathrm{M}$.

An alternative version of this experiment is shown in Figure 8C. Here, when we applied MMG2-DPb while the muscle was not being stimulated to contract, it had no effect. The MMG2-DPb-induced contracture appeared in an all-or-none manner only after the muscle was stimulated to contract.

In the MALDI analysis of the pedal neurons, we had detected two distinct peaks corresponding to the pyro-Glu and non-pyroGlu forms of MMG2-DPb. In these experiments on the ARC muscle, we used the pyro-Glu form. In a separate group of experiments, however, we verified that the non-pyro-Glu form of MMG2-DPb had qualitatively similar effects (data not shown).

\section{Central action of MMG2-DPs}

The buccal feeding CPG produces both ingestive and egestive motor programs. Both types of motor programs consist of a radula-protraction phase, marked by activity in the $\mathrm{I} 2$ nerve (Fig. $9 A$, white bar), followed by a radula-retraction phase, marked by activity in buccal nerve 2 (Fig. $9 A$, black bar). In the first series of experiments, we elicited a single motor program every $60 \mathrm{~s}$ by stimulating the esophageal nerve. In these motor programs, the radula closer motor neuron B8 fired predominantly during the protraction phase, and neurons B4/5 fired at high frequency during the retraction phase (Fig. $9 A$, control). Thus, these programs were considered to be egestive by criteria established previously (Morton and Chiel, 1993a,b; Jing and Weiss, 2001; Morgan et al., 2002). We then perfused an equimolar mixture of the four MMG2-DPs. This changed the motor program in several ways (Fig. 9A, $10^{-6} \mathrm{M}$ MMG2-DPs). First, the protraction phase became longer. Second, the B8 firing frequency during the retraction phase increased dramatically. Third, the B4/5 firing frequency during the retraction phase decreased. After washout of the MMG2-DPs, the motor programs recovered (Fig. 9A, wash). Figure $9 B$ shows the group data. To establish statistically significant differences between the control, MMG2-DP, and washout groups, we performed a one-way ANOVA of B8 firing frequency in the retraction phase $(n=4 ; F=6.62 ; \mathrm{df}=2,9 ; p<0.05), \mathrm{B} 4 / 5$ firing frequency in the retraction phase $(n=4 ; F=25.15 ; \mathrm{df}=2$, $9 ; p<0.0005)$, and protraction phase duration $(n=6 ; F=7.78$; $\mathrm{df}=2,15 ; p<0.005)$. The ANOVA was followed by two-tailed $t$ tests with Bonferroni's correction. The groups compared in the post hoc $t$ tests are shown in Figure $9 B\left({ }^{*} p<0.05\right)$. Figure $9 C$ 

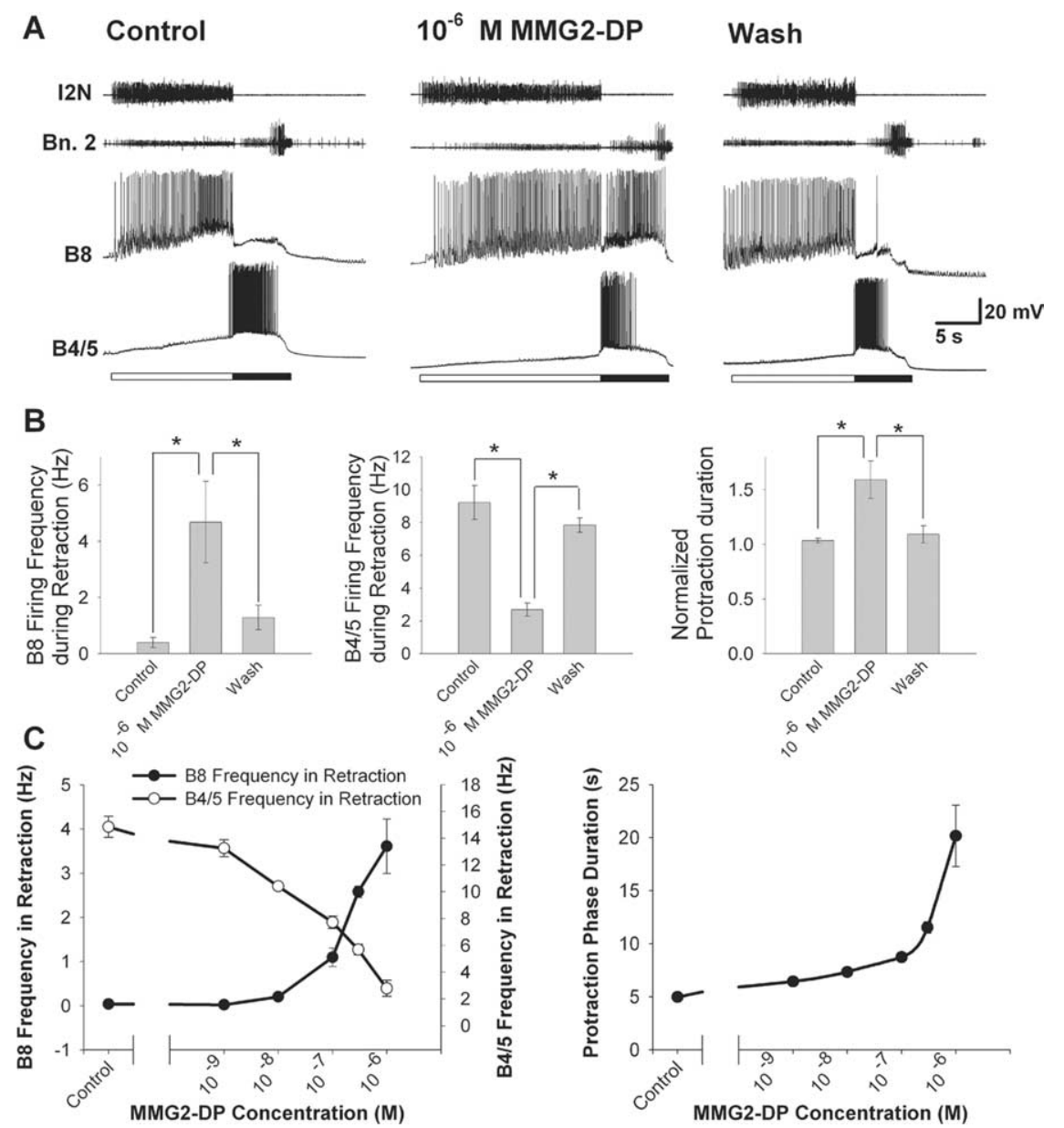

Figure 9. Effects of the MMG2-DPs on esophageal nerve-elicited egestive motor programs. $\boldsymbol{A}$, Representative recordings. Extracellular recordings of activity in the $\mathrm{I} 2$ nerve (I2N) and in buccal nerve 2 (Bn.2) and intracellular recordings of $B 8$ and $B 4 / 5$ firing were obtained simultaneously. The white bars mark the protraction phase, coincident with the activity in the 12 nerve. The black bars show the retraction phase, coincident with the activity in Bn.2. B, Group data of the effects of the MMG2-DPs on the $B 8$ firing frequency in retraction, $B 4 / 5$ firing frequency in retraction, and protraction duration. Error bars show the SE $(n=4-6)$. All ANOVAs were statistically significant $(p<0.05)$. Brackets show the groups compared in post hoc $t$ tests. ${ }^{*} p<0.05$, statistical significance. $C$, Dose dependence of the three effects of the MMG2-DPs. Data are the means \pm SE from 4-10 preparations.

shows the dose-response curves for the three effects of the MMG2-DPs.

In three separate experiments, the application of MMG2-DPs had no effects on ingestive motor programs that were elicited by the stimulation of the command-like CBI-2 neuron (data not shown). Thus, the net effect of the MMG2-DPs was to make the egestive motor programs elicited by esophageal nerve stimulation more ingestive. This is evidenced by both the increase of B8 firing and the concurrent decrease of $\mathrm{B} 4 / 5$ firing in the retraction phase. We next tested whether the MMG2-DP-elicited decrease in B4/5 firing frequency could be attributable to a direct effect on B4/5 excitability. Every minute, we injected a suprathreshold current pulse into B4/5. Some of these experiments, such as that in Figure $10 \mathrm{~A}$, were performed in saline containing high concentrations of divalent ions to diminish synaptic activity. Application of the MMG2-DPs decreased the number of action potentials elicited by the pulse (Fig. $10 A, 10^{-6} \mathrm{M}$ MMG2-DPs). Washout of the MMG2-DPs reversed the effect (Fig. $10 A$, washout). Figure $10 B$ shows the group data collected in eight experiments (one-way ANOVA; $n=8 ; F=74.07 ; \mathrm{df}=2,21 ; p<0.0001$ ). Thus, the MMG2-DPs appear to act directly on B4/5 to decrease its excit- ability. This decrease in excitability may contribute to the decrease of B4/5 firing in motor programs. In a similar experimental paradigm, the application of the MMG2DPs did not have any effect on the excitability of B8 (data not shown). Previous work has shown that B4/5 monosynaptically inhibits B8 (Jing and Weiss, 2001). Thus, the decrease in B4/5 firing in turn may contribute to the increase of $\mathrm{B} 8$ firing in the retraction phase of motor programs.

The central effects of MMG2-DPs are inherently more complex than their peripheral actions at the ARC muscle. It is likely that the MMG2-DPs simultaneously affect a number of different neurons and synaptic connections to produce the observed changes in the motor programs. Different MMG2-DPs can affect different subsets of neurons and synapses. Furthermore, some MMG2-DPs may turn out to be not bioactive at all in the CNS. Delineation of all of these possibilities will require systematic characterization of the actions of different MMG2-DPs on a number of known components of the feeding CPG. This will be an interesting avenue to pursue in the future.

\section{Discussion}

Here, we have described a new gene, $M M G 2$, that encodes a set of neuropeptides that can modulate both the CPG and the neuromuscular system involved in the generation of feeding behaviors in Aplysia. This gene encodes MMc and MMe, two neuropeptides that were originally purified from the ARC muscle, and four neuropeptides that were unknown previously (MMG2-DPa, MMG2-DPb, MMG2-DPd, and MMG2-DPf). MALDI analysis of the neurons that express MMG2 has revealed peaks that correspond to the amidated forms of both MMc and MMe as well as MMG2-DPa-f, arguing that these peptides are actually cleaved from the precursor and undergo post-translational modification typical of bona fide neuropeptides. Cloning and sequencing of the MMG2 precursor has allowed us to match the MMG2-DPs to unassigned MALDI peaks detected previously in the analysis of the cerebro-buccal and pedal-abdominal connectives ( $\mathrm{Li}$ et al., 1998; Sweedler et al., 2002). The presence of the MMG2-DPs in the connectives suggests that they are actively transported to different parts of the nervous system.

Indeed, using the newly generated MMG2-DP-specific antibodies, we have shown that neuronal processes containing these peptides are found in the neuropil of all of the major ganglia and in all of the buccal nerves. In contrast to the very broad distribution of the MMG2-DPs, ISH has suggested that their source is limited to a very small set of neurons in the pedal and cerebral ganglion. Because the neurons in the cerebral ganglion were not located in the areas of the ganglion that contain the neurons that project to the feeding circuitry, here we have focused on the MMG2-DP-staining neurons in the pedal ganglion. By a combination of immunohistochemical and electrophysiological tech- 
niques, we have identified some of these neurons as P-BPNs. It has been shown previously by Robie et al. (2003) that these neurons project not only to the buccal ganglion but through most of the buccal nerves out to the buccal musculature. Our data, combined with those of Robie et al. (2003), make it very likely that these neurons are the source of the MMG2-DP-, MMc-, and MMe-containing innervation both centrally and peripherally in the feeding system, including in the ARC muscle from which MMc and MMe were originally purified.

Several sources of neuromodulation are already known to converge on the ARC muscle to affect various parameters of the ARC muscle contraction. In some cases, different peptides modulate the very same parameters. For instance, both the MMs and SCPs increase the amplitude and the relaxation rate of ARC contractions (Cropper et al., 1987a,b, 1991; Brezina et al., 1996). Multiple converging modulatory inputs with overlapping effects may seem redundant. Yet such convergence exists in many other systems (Nusbaum and Beenhakker, 2002). In the ARC system, we have demonstrated previously that the redundancy is only superficial. At the quantitative level, the effects of the modulators are not identical but only partially overlapping and furthermore have different dynamics. Using a combination of experimental and theoretical approaches, we have shown that the convergence of the modulators with these properties allows the ARC muscle contraction waveform to sample regions of the parameter space that would not be accessible with any single modulator (Brezina et al., 1996, 2005). Thus the combinatorial control by convergent modulation allows for greater flexibility of response.

At first glance, the effects of the peptides derived from MMG2 on the ARC muscle may also seem redundant. MMG2-DPb induces a baseline contracture, whereas previously we found (Brezina et al., 1995) that MMc and MMe have the opposite effect: they relax the contraction baseline. In addition, however, $\mathrm{MMc}$ and MMe also increase the amplitude and relaxation rate of the contractions, whereas MMG2-DPb does not. Thus, the overall effects of the peptides are not redundant. Furthermore, the two effects on the baseline contraction have qualitatively different dynamics. Although the relaxation of the baseline induced by $\mathrm{MMc}$ and MMe does not require activity of the motor neurons or muscle, the MMG2-DPb-induced contracture does. This type of activity dependence of modulator action has not been observed previously in the ARC muscle. The activity dependence allows these peptides derived from the same gene and likely to be coreleased to act preferentially in different contexts to endow the ARC muscle contractions with greater flexibility.

The modulation of the ARC muscle by neuropeptides released from the ARC motor neurons, such as the MMs and the small cardioactive peptides (SCPs), is a classic example of what has been termed intrinsic modulation (Cropper et al., 1987a; Katz et al., 1994). By its nature, intrinsic modulation produces local changes, such as changes in the contraction of a single muscle. In contrast, extrinsic modulation, stemming from higher-level neurons that are themselves not part of the circuit they modulate, can act globally at multiple levels of organization of the nervous system.

Here, we have identified the neurons that contain the MMG2DPs as well as MMc and MMe as P-BPNs. These neurons are not rhythmically active during feeding motor programs (Robie et al.,
2003) and are thus not an integral part of the feeding circuitry. Yet the P-BPNs send projections to the feeding system, including the buccal ganglion that contains the feeding CPG and through the buccal nerves to the feeding musculature. They are thus likely to modulate the feeding system both centrally and peripherally. Indeed, in addition of the peripheral effects, here we have demonstrated that the MMG2-DPs affect a number of different parameters of the feeding motor programs. The MMG2-DPs lengthen the protraction phase and switch egestive motor programs to ingestive ones. We have identified one target of MMG2-DP action, neuron B4/5, which may contribute to the switch in the character of the motor programs. Together with the effects on the musculature, these observations suggest that the MMG2-DP-containing P-BPNs are extrinsic modulatory neurons that act at multiple levels within the feeding system.

Previous work has identified another extrinsic modulatory influence on the feeding circuitry, the serotonergic MCC neurons (Weiss et al., 1975, 1978). The modulation by serotonin and the MCCs converges with that of the peptides derived from MMG2 on several levels. Serotonin and the MCCs modulate ARC muscle contractions, increasing their amplitude and relaxation rate (Weiss et al., 1978; Brezina et al., 1996). These effects therefore resemble those of MMc and MMe, which have also been identified here as extrinsic modulators. MCC stimulation and serotonin leads to several changes in the characteristics of the feeding motor programs, including a shortening of the protraction phase (Morgan et al., 2000). In this respect, the effect of the MCCs and serotonin is opposite to that of the MMG2-DPs. Like the MMG2DPs, the MCCs also modulate the neurons B4/5 (Weiss and Kupfermann, 1976). The feeding system may be simultaneously modulated by both extrinsic systems, because both the MCC and the P-BPNS are activated by C-PR, a neuron important for the appetitive phase of feeding behavior (Teyke et al., 1990; Hurwitz et al., 1999; Robie et al., 2003).

Thus, combined with the previous work, the discovery of the MMG2-DPs and the localization of these neuropeptides to the $\mathrm{P}-\mathrm{BPN}$ demonstrate that multiple extrinsic modulatory inputs converge both at the level of the feeding CPG and in the periphery. As with the intrinsic modulators of the ARC muscle, some of the effects are similar, but some appear superficially antagonistic. Thus, the analytical methods that we have applied in the ARC muscle system may be applicable more generally. Combined with the previous data, our results suggest that the principles of combinatorial control through convergent modulation observed in the ARC muscle system may be recapitulated at multiple levels of organization of the nervous system.

Convergence of multiple modulatory systems is a ubiquitous neuroanatomical motif observed both in invertebrate and vertebrate nervous systems. For instance, serotonergic fibers originat- 
ing from the raphe nuclei and noradrenergic fibers originating from the locus ceruleus converge to modulate motor neurons in the spinal cord (Holstege and Kuypers, 1987). Thus, extending the understanding of the consequences of convergence of multiple modulatory systems from the peripheral structures into the CNS in experimentally tractable preparations is likely to provide insight into the general principles of combinatorial control of behavioral plasticity.

\section{References}

Brezden BL, Yeoman MS, Gardner DR, Benjamin PR (1999) FMRFamideactivated $\mathrm{Ca}^{2+}$ channels in Lymnaea heart cells are modulated by "SEEPLY," a neuropeptide encoded on the same gene. J Neurophysiol 81:1818-1826.

Brezina V, Evans CG, Weiss KR (1994a) Enhancement of Ca current in the accessory radula closer muscle of Aplysia californica by neuromodulators that potentiate its contractions. J Neurosci 14:4393-4411.

Brezina V, Evans CG, Weiss KR (1994b) Activation of K current in the accessory radula closer muscle of Aplysia californica by neuromodulators that depress its contractions. J Neurosci 14:4412-4432.

Brezina V, Bank B, Cropper EC, Rosen S, Vilim FS, Kupfermann I, Weiss KR (1995) Nine members of the myomodulin family of peptide cotransmitters at the B16-ARC neuromuscular junction of Aplysia. J Neurophysiol 74:54-72.

Brezina V, Orekhova IV, Weiss KR (1996) Functional uncoupling of linked neurotransmitter effects by combinatorial convergence. Science 273:806-810.

Brezina V, Orekhova IV, Weiss KR (2003a) Neuromuscular modulation in Aplysia. I. Dynamic model. J Neurophysiol 90:2592-2612.

Brezina V, Orekhova IV, Weiss KR (2003b) Neuromuscular modulation in Aplysia. II. Modulation of the neuromuscular transform in behavior. J Neurophysiol 90:2613-2628.

Brezina V, Horn CC, Weiss KR (2005) Modeling neuromuscular modulation in Aplysia. III. Interaction of central motor commands and peripheral modulatory state for optimal behavior. J Neurophysiol 93:1523-1556.

Brown RS, Lennon JJ (1995) Mass resolution improvement by incorporation of pulsed ion extraction in a matrix-assisted laser desorption/ionization linear time-of-flight mass spectrometer. Anal Chem 67:1998-2003.

Chiel HJ, Kupfermann I, Weiss KR (1988) An identified histaminergic neuron can modulate the outputs of buccal-cerebral interneurons in Aplysia via presynaptic inhibition. J Neurosci 8:49-63.

Chomczynski P, Sacchi N (1987) Single-step method of RNA isolation by acid guanidinium thiocyanate-phenol-chloroform extraction. Anal Biochem 162:156-159.

Church PJ, Lloyd PE (1991) Expression of diverse neuropeptide cotransmitters by identified motor neurons in Aplysia. J Neurosci 11:618-625.

Church PJ, Whim MD, Lloyd PE (1993) Modulation of neuromuscular transmission by conventional and peptide transmitters released from excitatory and inhibitory motor neurons in Aplysia. J Neurosci 13:2790-2800.

Cropper EC, Lloyd PE, Reed W, Tenenbaum R, Kupfermann I, Weiss KR (1987a) Multiple neuropeptides in cholinergic motor neurons of Aplysia: evidence for modulation intrinsic to the motor circuit. Proc Natl Acad Sci USA 84:3486-3490.

Cropper EC, Tenenbaum R, Kolks MA, Kupfermann I, Weiss KR (1987b) Myomodulin: a bioactive neuropeptide present in an identified cholinergic buccal motor neuron of Aplysia. Proc Natl Acad Sci USA 84:5483-5486.

Cropper EC, Miller MW, Tenenbaum R, Kolks MA, Kupfermann I, Weiss KR (1988) Structure and action of buccalin: a modulatory neuropeptide localized to an identified small cardioactive peptide-containing cholinergic motor neuron of Aplysia californica. Proc Natl Acad Sci USA 85:6177-6181.

Cropper EC, Miller MW, Vilim FS, Tenenbaum R, Kupfermann I, Weiss KR (1990) Buccalin is present in the cholinergic motor neuron B16 of Aplysia and it depresses accessory radula closer muscle contractions evoked by stimulation of B16. Brain Res 512:175-179.

Cropper EC, Vilim FS, Alevizos A, Tenenbaum R, Kolks MA, Rosen S, Kupfermann I, Weiss KR (1991) Structure, bioactivity, and cellular localization of myomodulin B: a novel Aplysia peptide. Peptides 12:683-690.
Cropper EC, Brezina V, Vilim FS, Harish O, Price DA, Rosen S, Kupfermann I, Weiss KR (1994) FRF peptides in the ARC neuromuscular system of Aplysia: purification and physiological actions. J Neurophysiol 72:2181-2195.

Evans CG, Vilim FS, Harish O, Kupfermann I, Weiss KR, Cropper EC (1999) Modulation of radula opener muscles in Aplysia. J Neurophysiol 82:1339-1351.

Friedman AK, Proekt A, Brezina V, Jing J, Zhurov Y, Alexeeva V, Li L, Sweedler JV, Weiss KR, Vilim FS (2003) Identification and characterization of the orphan myomodulin precursor of Aplysia. Soc Neurosci Abstr 29:44.5.

Fujisawa Y, Furukawa Y, Ohta S, Ellis TA, Dembrow NC, Li L, Floyd PD, Sweedler JV, Minakata H, Nakamaru K, Morishita F, Matsushima O, Weiss KR, Vilim FS (1999) The Aplysia Mytilus inhibitory peptiderelated peptides: identification, cloning, processing, distribution, and action. J Neurosci 19:9618-9634.

Furukawa Y, Nakamaru K, Wakayama H, Fujisawa Y, Minakata H, Ohta S, Morishita F, Matsushima O, Li L, Romanova E, Sweedler JV, Park JH, Romero A, Cropper EC, Dembrow NC, Jing J, Weiss KR, Vilim FS (2001) The enterins: a novel family of neuropeptides isolated from the enteric nervous system and CNS of Aplysia. J Neurosci 21:8247-8261.

Holstege JC, Kyupers HG (1987) Brainstem projections to spinal motoneurons: an update. J Neurosci 23:809-821.

Horn CC, Zhurov Y, Orekhova IV, Proekt A, Kupfermann I, Weiss KR, Brezina V (2004) Cycle-to-cycle variability of neuromuscular activity in Aplysia feeding behavior. J Neurophysiol 92:157-180.

Hummon AB, Kelley WP, Sweedler JV (2002) A novel prohormone processing site in Aplysia californica: the Leu-Leu rule. J Neurochem 82:1398-1405.

Hurwitz I, Susswein AJ (1996) B64, a newly identified central pattern generator element producing a phase switch from protraction to retraction in buccal motor programs of Aplysia californica. J Neurophysiol 75:1327-1344.

Hurwitz I, Neustadter D, Morton DW, Chiel HJ, Susswein AJ (1996) Activity patterns of the B31/B32 pattern initiators innervating the I2 muscle of the buccal mass during normal feeding movements in Aplysia californica. J Neurophysiol 75:1309-1326.

Hurwitz I, Kupfermann I, Susswein AJ (1997) Different roles of neurons B63 and B34 that are active during the protraction phase of buccal motor programs in Aplysia californica. J Neurophysiol 78:1305-1319.

Hurwitz I, Perrins R, Xin Y, Weiss KR, Kupfermann I (1999) C-PR neuron of Aplysia has differential effects on "feeding" cerebral interneurons, including myomodulin-positive CBI-12. J Neurophysiol 81:521-534.

Hurwitz I, Cropper EC, Vilim FS, Alexeeva V, Susswein AJ, Kupfermann I, Weiss KR (2000) Serotonergic and peptidergic modulation of the buccal mass protractor muscle (I2) in Aplysia. J Neurophysiol 84:2810-2820.

Jing J, Weiss KR (2001) Neural mechanisms of motor program switching in Aplysia. J Neurosci 21:7349-7362.

Jing J, Weiss KR (2002) Interneuronal basis of the generation of related but distinct motor programs in Aplysia: implications for current neuronal models of vertebrate intralimb coordination. J Neurosci 22:6228-6238.

Katz PS, Getting PA, Frost WN (1994) Dynamic neuromodulation of synaptic strength intrinsic to a central pattern generator circuit. Nature 367:729-731.

Koh HY, Vilim FS, Jing J, Weiss KR (2003) Two neuropeptides colocalized in a command-like neuron use distinct mechanisms to enhance its fast synaptic connection. J Neurophysiol 90:2074-2079.

Li L, Moroz TP, Garden RW, Floyd PD, Weiss KR, Sweedler JV (1998) Mass spectrometric survey of interganglionically transported peptides in Aplysia. Peptides 19:1425-1433.

Li L, Romanova EV, Rubakhin SS, Alexeeva V, Weiss KR, Vilim FS, Sweedler JV (2000) Peptide profiling of cells with multiple gene products: combining immunochemistry and MALDI mass spectrometry with on-plate microextraction. Anal Chem 72:3867-3874.

Li L, Floyd PD, Rubakhin SS, Romanova EV, Jing J, Alexeeva VY, Dembrow NC, Weiss KR, Vilim FS, Sweedler JV (2001) Cerebrin prohormone processing, distribution and action in Aplysia californica. J Neurochem 77:1569-1580.

Miller MW, Alevizos A, Cropper EC, Vilim FS, Karagogeos D, Kupfermann I, Weiss KR (1991) Localization of myomodulin-like immunoreactivity in the central nervous system and peripheral tissues of Aplysia californica. J Comp Neurol 314:627-644. 
Miller MW, Alevizos A, Cropper EC, Kupfermann I, Weiss KR (1992) Distribution of buccalin-like immunoreactivity in the central nervous system and peripheral tissues of Aplysia californica. J Comp Neurol 320:182-195.

Miller MW, Beushausen S, Vitek A, Stamm S, Kupfermann I, Brosius J, Weiss KR (1993) The myomodulin-related neuropeptides: characterization of a gene encoding a family of peptide cotransmitters in Aplysia. J Neurosci 13:3358-3367.

Morgan PT, Perrins R, Lloyd PE, Weiss KR (2000) Intrinsic and extrinsic modulation of a single central pattern generating circuit. J Neurophysiol 84:1186-1193.

Morgan PT, Jing J, Vilim FS, Weiss KR (2002) Interneuronal and peptidergic control of motor pattern switching in Aplysia. J Neurophysiol $87: 49-61$

Morton DW, Chiel HJ (1993a) In vivo buccal nerve activity that distinguishes ingestion from rejection can be used to predict behavioral transitions in Aplysia. J Comp Physiol 172:17-32.

Morton DW, Chiel HJ (1993b) The timing of activity in motor neurons that produce radula movements distinguishes ingestion from rejection in Aplysia. J Comp Physiol 173:519-536.

Nielsen H, Engelbrecht J, Brunak S, von Heijne G (1997) Identification of prokaryotic and eukaryotic signal peptides and prediction of their cleavage sites. Protein Eng 10:1-6.

Nusbaum MP, Beenhakker MP (2002) A small-systems approach to motor pattern generation. Nature 417:343-350.

Orekhova IV, Alexeeva V, Church PJ, Weiss KR, Brezina V (2003) Multiple presynaptic and postsynaptic sites of inhibitory modulation by myomodulin at ARC neuromuscular junctions of Aplysia. J Neurophysiol 89:1488-1502.

Proekt A, Weiss KR (2003) Convergent mechanisms mediate preparatory states and repetition priming in the feeding network of Aplysia. J Neurosci 23:4029-4033.

Proekt A, Brezina V, Weiss KR (2004) Dynamical basis of intentions and expectations in a simple neuronal network. Proc Natl Acad Sci USA 101:9447-9452.

Robie A, Díaz-Ríos M, Miller MW (2003) A population of pedal-buccal projection neurons associated with appetitive components of Aplysia feeding behavior. J Comp Physiol A Neuroethol Sens Neural Behav Physiol 189:231-244.

Rosen SC, Teyke T, Miller MW, Weiss KR, Kupfermann I (1991) Identification and characterization of cerebral-to-buccal interneurons impli- cated in the control of motor programs associated with feeding in Aplysia. J Neurosci 11:3630-3655.

Sambrook J, Fritsch EF, Maniatis T (1989) Molecular cloning: a laboratory manual. New York: Cold Spring Harbor Laboratory.

Spengler B (1997) Post-source decay analysis in matrix-assisted laser desorption/ionization mass spectrometry of biomolecules. J Mass Spectrom 32:1019-1036.

Strand FL (1999) Neuropeptides: regulators of physiological processes. Cambridge, MA: MIT.

Sweedler JV, Li L, Rubakhin SS, Alexeeva V, Dembrow NC, Dowling O, Jing J, Weiss KR, Vilim FS (2002) Identification and characterization of the feeding circuit-activating peptides, a novel neuropeptide family of Aplysia. J Neurosci 22:7797-7808.

Teyke T, Weiss KR, Kupfermann I (1990) An identified neuron (CPR) evokes neuronal responses reflecting food arousal in Aplysia. Science 247:85-87.

Vilim FS, Price DA, Lesser W, Kupfermann I, Weiss KR (1996) Costorage and corelease of modulatory peptide cotransmitters with partially antagonistic actions on the accessory radula closer muscle of Aplysia californica. J Neurosci 16:8092-8104.

Vilim FS, Cropper EC, Price DA, Kupfermann I, Weiss KR (2000) Peptide cotransmitter release from motorneuron B16 in Aplysia californica: costorage, corelease, and functional implications. J Neurosci 20:2036-2042.

Vilim FS, Alexeeva V, Moroz LL, Li L, Moroz TP, Sweedler JV, Weiss KR (2001) Cloning, expression and processing of the CP2 neuropeptide precursor of Aplysia. Peptides 22:2027-2038.

Weiss KR, Kupfermann I (1976) Homology of the giant serotonergic neurons (metacerebral cells) in Aplysia and pulmonate molluscs. Brain Res 117:33-49.

Weiss KR, Cohen J, Kupfermann I (1975) Potentiation of muscle contraction: a possible modulatory function of an identified serotonergic cell in Aplysia. Brain Res 99:381-386.

Weiss KR, Cohen JL, Kupfermann I (1978) Modulatory control of buccal musculature by a serotonergic neuron (metacerebral cell) in Aplysia. J Neurophysiol 41:181-203.

Weiss KR, Mandelbaum DE, Schonberg M, Kupfermann I (1979) Modulation of buccal muscle contractility by serotonergic metacerebral cells in Aplysia: evidence for a role of cyclic adenosine monophosphate. J Neurophysiol 42:791-803. 